\title{
Alfabetización entre personas jóvenes y adultas
}

\author{
Literacy among Young People and Adults
}

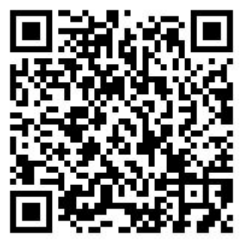

\author{
Luz Emilia Flores-Davis ${ }^{1}$ \\ Universidad Nacional \\ Rectoría \\ Heredia, Costa Rica \\ luz.flores.davis@una.cr
}

Recibido 31 de agosto de 2014 • Corregido 1 de setiembre de 2015 • Aceptado 17 de noviembre de 2015

Resumen. El presente artículo tiene como propósito compartir vivencias y reflexiones realizadas durante más de veinte años trabajando el tema de la alfabetización entre personas jóvenes y adultas, así como ofrecer ideas que puedan favorecer nuevas experiencias. La alfabetización entre personas adultas es una práctica de convivencia donde aprenden tanto el mediador o la mediadora como quien aprende. Cada ejercicio de mediar el aprendizaje de la lectoescritura es único, por lo cual la ruta del nombre propio que aquí se comparte debe ser contextualizada. Las premisas fundamentales que se desarrollan en este artículo tienen que ver con el derecho de toda persona de aprender a leer y a escribir su propia realidad, desde sus circunstancias y sus sueños, o sea, desde sus vivencias, ideas, conocimientos, sentires y esperanzas. Lo anterior implica ubicar a la persona aprendiente como centro del proceso pedagógico y, por lo tanto, respetar sus intereses, necesidades y ritmos de aprendizaje.

Palabras claves. Alfabetización, personas adultas, lectoescritura, ruta del nombre propio.

Abstract. This article aims to share experiences and reflections carried out during over twenty years of working in the literacy issue among young people and adults, as well as offering ideas that can foster new experiences. Literacy among adults is a practice of coexistence where both the mediator and the student learn. Each literacy learning mediation exercise is unique; therefore the path to the proper name shared here must be contextualized. The basic premises which are developed in this article have to do with the right of every person to learn how to read and write his/her own reality, depicted from their circumstances and dreams; in other words, from their experiences, ideas, expertise, feelings and hopes. The latter involves locating the learner person as the center of the learning process and, hence, respecting his/her interests, needs and learning pace.

Keywords. Literacy, adults, reading and writing, proper name route.

\footnotetext{
${ }^{1}$ Doctora en Educación con especialidad en Mediación Pedagógica. Máster en Educación Superior. Catedrática universitaria. Ha ocupado los cargos de directora de Docencia, directora de Desarrollo Profesional y Cooperación Universitaria, presidenta de la Junta de Becas y coordinadora de la Comisión Técnica de Admisión de la Universidad Nacional. Se desempeña como investigadora, extensionista y docente en la División de Educación Básica del Centro de Investigación y Docencia en Educación de la Universidad Nacional, Costa Rica. Actualmente es la rectora adjunta de la Universidad Nacional. Entre sus publicaciones destacan trabajos para la alfabetización de personas adultas.
} 
doi: http://dx.doi.org/10.15359/ree.20-1.22

URL: http://www.una.ac.cr/educare

CORREO: educare@una.cr

Enseñar a leer y a escribir a una persona adulta es una experiencia enriquecedora que proporciona enorme satisfacción, al contribuir con la responsabilidad social de una educación para todos y para todas.

Es gratificante para un mediador o una mediadora observar la sonrisa de un o una aprendiente que se sorprende al leer una nueva palabra, o las lágrimas de quien lee por primera vez una carta guardada tiempo atrás. Así como enterarse de que la persona que se alfabetiza ya puede salir de su casa sin temor, o tomar sola el autobús, o firmar la lista de asistencia en las reuniones de la escuela de sus hijos, o firmar su cédula de identidad, o leer la biblia en su iglesia, o que ya puede tomarse las medicinas sin que alguien más le lea las etiquetas, o hacer la lista del supermercado, o leerle un cuento a sus hijos, o mandar un mensaje de texto. Escuchar a quien aprende decir que, al saber leer y escribir, consiguió un trabajo, o que puede cantar en karaoke, o que su familia "le respeta", o que quiere seguir estudiando..., saberse parte de la historia de vida de una persona adulta, hasta hace poco tiempo marginada por la sociedad e invisibilizada, que ahora se sabe capaz de luchar por lo que quiere, es algo que no tiene parangón.

Aprender a leer y escribir es abrir camino hacia nuevos horizontes, esperanzas y oportunidades. Es hacer los sueños realidad y reconocer que nunca es demasiado tarde para aprender. Significa poder desenvolverse en sociedad como las demás personas de su entorno, desde sus coincidencias y sus diferencias. Es tomar conciencia del derecho a la ciudadanía, a las oportunidades, a expresarse con libertad.

Ciudadanía supone pues conciencia de responsabilidad cívica. Es como la parábola del niño que, en la playa, devolvía al mar uno tras otro los pececitos que la marea había arrojado a la arena. Alguien le dijo: “QQué adelantas con eso? No vas a poder salvarlos a todos". A lo que el niño respondió: "Ya lo sé. Pero éste -y le mostró un pececito que bailaba en su mano- estará a salvo". Y lo devolvió al agua. (Frei Betto, 2006, párr. 1)

Freire (1991) nos dice que la alfabetización es un acto de conocimiento, un acto político $y$, por lo tanto, un acto creador, y que la lectura del mundo precede a la lectura de la palabra. También expresa que la lectura de la palabra implica la continuidad de la lectura del mundo, pues hay una relación dinámica entre la palabra y la realidad. Freire (1991) invita a asumir la alfabetización como herramienta para la liberación del ser humano, aspecto vital para despertar del letargo adormecedor del consumismo, del materialismo, y del determinismo propio de la sociedad que domestica. No temerle a la libertad y abrirse a la creatividad son imperativos éticos tanto de quien se alfabetiza como del mediador o mediadora de los aprendizajes.

El esfuerzo que realizamos para que la persona aprendiente lea las palabras está entrelazado con el esfuerzo por promover que lea y renueve su realidad. "Es así como la vida se ha ido transformando en una acción en el mundo desarrollada por sujetos que poco a poco han ido ganando conciencia de su propio hacer sobre el mundo" (Freire, 2004a, p. 113).

2

Luz Emilia Flores-Davis

(c) (1) (3) 
El presente artículo tiene como propósito compartir reflexiones realizadas durante más de veinte años trabajando el tema de la alfabetización de personas adultas y ofrecer ideas que pueden favorecer nuevas experiencias. Cada vivencia de mediar el aprendizaje de la lectoescritura es única, por lo cual lo que aquí se comparte debe ser contextualizado. Las premisas fundamentales que se desarrollan tienen que ver con el derecho de toda persona de aprender a leer y a escribir su realidad y desde su realidad, o sea, desde sus vivencias, ideas, conocimientos, sentires y esperanzas. Lo anterior implica el requerimiento de ubicar a la persona aprendiente como centro del proceso pedagógico y, por lo tanto, respetar sus intereses, necesidades, y ritmos de aprendizaje.

\section{Acuerdo preliminar para la alfabetización entre personas jóvenes y adultas}

Realizar una experiencia de alfabetización entre personas jóvenes y adultas transforma la vida de quien aprende a leer y escribir, así como también la vida de quien realiza la mediación pedagógica. Es un reto que requiere compromiso y entusiasmo de ambas partes participantes.

Para quien alfabetiza por primera vez, es comprensible tener una sensación de incertidumbre e incluso de temor, la cual irá transformándose, conforme avance el proceso. Como dice Morin (2001): "El conocimiento es navegar en un océano de incertidumbres a través de archipiélagos de certezas" (p. 104).

Con referencia al miedo, Freire (2004a) plantea que:

La cuestión que aquí se plantea no es negar el miedo, aún cuando el peligro que lo genera sea ficticio. El miedo en sí, sin embargo, es concreto. La cuestión que presenta es la de no permitir que el miedo nos paralice o nos persuada fácilmente de desistir de enfrentar la situación desafiante sin lucha y sin esfuerzo. (pp. 44-45)

Para quien va a aprender a leer y escribir siendo una persona adulta puede significar una gran alegría por no haber tenido antes la oportunidad de que alguien le enseñara, o puede suponer una nueva opción ante fracasos anteriores. En este último caso, es vital que la persona comprenda que si no ha aprendido antes, ello no implica que no pueda aprender ahora. Como se desprende de lo anterior, realizar una experiencia de mediación pedagógica demanda gran entrega y responsabilidad.

Al iniciar un proceso de alfabetización de una persona joven o adulta, debemos tener presente que no estaremos enseñando a leer y escribir a un niño o niña. Y, por lo tanto, debemos reconocer lo que significa ser una persona adulta, sus gustos, intereses, experiencias, para actuar siempre en apego a ello. 
doi: http://dx.doi.org/10.15359/ree.20-1.22

URL: http://www.una.ac.cr/educare

CORREO: educare@una.cr

Si bien existen principios metodológicos para la mediación de la lectoescritura inicial que pueden ser efectivos tanto con niños, niñas o personas jóvenes y adultas, tales como partir de los conocimientos previos, tomar en cuenta los intereses, incluir elementos lúdicos, respetar los ritmos de aprendizaje, es indispensable tomar en cuenta las diferencias entre los niños y las niñas, y las personas adultas, si queremos promover un aprendizaje positivo. En este sentido, hay que darle especial importancia al vocabulario utilizado: con las personas adultas no debemos usar términos para la escritura, propios de la infancia o de los intereses infantiles.

Respecto a la situación del aprendizaje de la persona adulta, Amador, Monreal y Marco (2001) expresan que la persona adulta no disminuye su capacidad de aprendizaje con respecto al joven, sino que se encuentra en una situación de aprendizaje diferente, debido a que tiene otro tipo de intereses y necesidades; requiere otras formas de aprendizaje, pues tiene una relación más conservadora frente a los aprendizajes.

En el ámbito de lo que significa ser adulta o adulto encontramos múltiples interpretaciones. Tengamos presente que cada persona es única, como únicas son sus circunstancias, experiencias, creencias, y expectativas. Pero, en términos generales, podemos ubicar diferencias entre alfabetizar a una persona adulta o adulta-joven; y una persona adulta-mayor. Así como también si la persona tiene o no alguna discapacidad cognitiva y, en ese caso, si es leve, moderada o severa.

En este sentido, la persona adulta o adulta-joven usualmente tiene deseos de aprender a leer y escribir rápidamente y pone, entonces, todo su empeño en un proceso de alfabetización concentrado en la lectura y escritura, dedicando mucho de su tiempo y esfuerzo en ello.

Por su parte, la persona adulta-mayor, o sea mayor de 65 años, en términos ordinarios, más bien prefiere realizar un proceso a un ritmo de aprendizaje más lento, y dedicar la mayor parte de las sesiones de alfabetización a la conversación.

De igualmanera, en situaciones dealfabetización con personas que presentan discapacidad cognitiva, se debe especialmente atender su ritmo de aprendizaje en concordancia con sus características particulares.

A pesar de las especificidades expresadas en los párrafos anteriores, podemos hablar en términos generales de la alfabetización de personas adultas, y así, en todos los casos, se deben realizar, en cada una de las sesiones, actividades de lectura, escritura, conversación y trabajo lúdico-manual; lo que varía según si estamos trabajando con una persona adulta-joven, adulta, o adulta-mayor, y con discapacidad cognitiva o sin esta, es el tiempo que dedicamos a cada una de esas actividades.

Asimismo, es fundamental tener presente que la persona adulta se caracteriza, entre otras cosas, por la capacidad de tomar sus propias decisiones. Por tanto, el respeto en el amplio sentido de la palabra debe marcar la relación pedagógica a lo largo de todo el proceso de alfabetización. La persona adulta debe tener una participación activa en su proceso de 
aprendizaje; es copartícipe de las actividades; conviene preguntarle constantemente si se siente a gusto con las actividades que estamos realizando, qué propone, qué opina.

Una actitud de apertura y de respeto hacia la persona irá fortaleciendo, también, su autonomía y evidenciará que nos interesa lo que piensa y cómo se siente; que nos importa como persona y no solo como "estudiante"; que valoramos sus experiencias, sus actividades laborales, su forma de vida. "El respeto a la autonomía y a la dignidad de cada uno es un imperativo ético y no un favor que podemos o no concedernos unos a los otros" (Freire, 2004b, p. 58).

Es indispensable vivenciar procedimientos horizontales. Las relaciones entre personas jóvenes y adultas se favorecen si estas son democráticas, centradas en el diálogo, y con justa valoración de las distintas capacidades. Así, el mediador o la mediadora promueve el aprendizaje de la lectura y escritura, y el aprendiente o la aprendiente le puede enseñar, a su vez, lo que sabe hacer muy bien, por ejemplo, cocinar, sembrar una planta, arreglar un artefacto, entre otros.

Todo proceso de alfabetización necesita organización, por lo cual se debe establecer el horario y lugar de las sesiones. El horario debe respetarse en la medida de lo posible, pues el aprendizaje de la lectura y escritura necesita constancia. No obstante, retomando lo dicho de la persona adulta y de sus necesidades personales, puede haber ocasiones en las cuales se trabaje más horas que en otras, dependiendo del estado de ánimo o cansancio que manifieste la persona aprendiente. Quien enseña debe estar atento a esas manifestaciones, pues el aprendizaje, primero que todo, debe ser placentero.

Por otra parte, si no se puede realizar una sesión, esta debe reprogramarse a la mayor brevedad posible. Y por supuesto de mutuo acuerdo.

En cuanto al espacio físico donde se lleven a cabo las sesiones de alfabetización es necesario que sea un lugar donde, tanto quien enseña como quien aprende sientan seguridad, tranquilidad, confort, que tengan privacidad y no se les esté interrumpiendo constantemente. Debe buscarse un lugar con esas características o solicitar el apoyo de otras personas para que durante las sesiones se pueda contar con esas condiciones.

\section{Principios de aprendizaje de la lectoescritura}

El proceso de aprendizaje de la lectoescritura, además de realizarse en contextos socioculturales específicos que requieren ser incorporados en la mediación pedagógica, debe tomar en cuenta también los procesos evolutivos propios de su construcción.

En este sentido son fundamentales los aportes de Ferreiro (1997), quien revela que cuando hablamos de escritura no se hace referencia solamente a la producción de marcas gráficas, sino de interpretación de estas mismas: "Escribir es construir una representación según una serie de reglas socialmente codificadas; leer es construir una realidad lingüística a partir de la interpretación de los elementos provistos por la representación" (Ferreiro, 2007, p. 252). 
doi: http://dx.doi.org/10.15359/ree.20-1.22

URL: http://www.una.ac.cr/educare

CORREO: educare@una.cr

Ferreiro (1997) demuestra en sus investigaciones que a pesar de que existen grandes variaciones en las edades en que aparecen las distintas conceptualizaciones de la escritura, las secuencias se mantienen. Nos dice que se puede afirmar que hay construcción de la lengua escrita dado que se ha demostrado que las conceptualizaciones no son posibles de justificar por la transmisión de personas alfabetizadas, ni por una lectura directa del ambiente.

De lo anteriormente expresado se desprende, entre otras cosas, la necesidad de mediar el aprendizaje de la lectura y de la escritura a partir de las ideas que tienen las personas respecto a los conceptos que se estudian. Propiciar que se expresen es entonces fundamental.

Hay que recalcar que la copia sin comprensión, no es escritura, y que la lectura y la escritura deben abordarse de manera simultánea en la alfabetización. “Uno de los errores que cometemos es el de dicotomizar el leer del escribir, y (...) tomamos estos procesos como algo desconectado del proceso general del conocer" (Freire, 2004a, p. 40).

El biólogo Humberto Maturana (2001) señala que, tradicionalmente, por no entender el lenguaje como fenómeno biológico, se piensa que el lenguaje es un sistema de comunicación simbólico y que "los símbolos son entidades abstractas que nos permiten movernos en un espacio de discursos, flotante sobre la concreción del vivir aunque lo representen" (p. 64).

Al respecto dicho autor afirma que:

En efecto, el lenguaje, como fenómeno que nos involucra como seres vivos y, por lo tanto, como un fenómeno biológico que se origina en nuestra historia evolutiva, consiste en un operar recurrente, en coordinaciones de coordinaciones conductuales consensuales. De esto resulta que las palabras son nodos en redes de coordinación de acciones, no representantes abstractos de una realidad independiente de nuestro quehacer. (Maturana, 2001, p. 64)

Se aprende mejor cuando se le encuentra sentido a lo que se está aprendiendo, cuando el aprendizaje es pertinente. En la alfabetización de personas adultas, tomar en cuenta este principio es primordial, pues la condición de adultez conlleva entender lo que se está haciendo.

Ligado a lo anterior, y como hemos mencionado, se encuentra la necesidad de que los aprendizajes estén contextualizados, que formen parte cercana de quien aprende. Por ello es necesario conocer los intereses y las necesidades de la persona que se está alfabetizando. Intereses y necesidades son la fuente principal para establecer la metodología de trabajo.

Durante la mediación pedagógica conviene utilizar una variedad de experiencias de aprendizaje, que incluyan la sorpresa y el gusto por descubrir cosas nuevas. Si bien es conveniente establecer ciertas rutinas, introducir de vez en cuando alguna actividad novedosa despierta la alegría de aprender.

6 
Es necesario también tener presente el papel del error en el proceso de aprendizaje. El error es parte consustancial del proceso de aprendizaje. Mientras se está aprendiendo es natural que se presenten errores ante los ojos de quien ya sabe o de quien enseña. Desde esta perspectiva, el error es solamente un eslabón para llegar al aprendizaje. Para quien enseña es de gran importancia considerar el "error", pues este le indica lo que está pensando el sujeto aprendiente, $y$ le permite mediar a partir de esa idea.

Esto nos lleva a otro principio básico del aprendizaje: partir del conocimiento previo o conocimiento del estudiante. Los aprendizajes se construyen sobre la base de lo que ya se sabe, por ello para mediar necesitamos saber lo que la persona cree sobre los conceptos que se están abordando. Es a partir de ahí que podemos propiciar el nuevo conocimiento.

El placer de aprender, la pasión con la cual realizamos una actividad es un componente vital del aprendizaje.

El aprendizaje es un proceso corporal: aprendemos con todos nuestros sentidos; una atmósfera de tensión genera rigidez en el cuerpo, así como lo contrario, un ambiente pedagógico placentero, propicia relajación y situaciones favorables para el aprendizaje. (Flores, 2010, pp. 44-45)

\section{Consideraciones en la alfabetización de personas jóvenes y adultas}

\section{Autoestima}

Muchas personas adultas que no han aprendido a leer y a escribir usualmente piensan que no tienen la capacidad necesaria para aprender como las demás, y en no pocas oportunidades sus familiares o amistades refuerzan esa opinión, lo cual incluso se traslada a otras actividades cotidianas y limitan su participación en ellas. Esta creencia dificulta el aprendizaje y, por lo tanto, como mediadores o mediadoras, debemos hacérselos ver. Para ello, lo primero es saber, nosotros mismos o nosotras mismas, que todas las personas podemos aprender, aunque a diferentes ritmos y de diversas maneras. No todos y todas aprendemos al mismo tiempo ni del mismo modo.

Si somos conscientes de ello, debemos adecuarnos a los tiempos de aprendizaje de la persona que estamos alfabetizando. Podemos tener una ruta de aprendizaje prevista y planificar las sesiones, pero será el avance de la persona aprendiente el que establece cuánto tiempo dedicamos a cada actividad. No se trata de ejecutar lo planeado a toda costa, sino de ser un medio entre quien aprende y lo que está aprendiendo. Ser facilitadores de la construcción de los aprendizajes, sabiendo que nadie puede aprender por otro. La persona aprendiente es realmente protagonista de su proceso de aprendizaje. 
doi: http://dx.doi.org/10.15359/ree.20-1.22

URL: http://www.una.ac.cr/educare

CORREO: educare@una.cr

Es conveniente conversar con la persona aprendiente acerca de las razones por las cuales no ha aprendido antes a leer y escribir. Posiblemente así empiece a descubrir las verdaderas razones, tales como la situación económica de sus padres; la necesidad que tuvo de colaborar en los quehaceres de su casa, o de trabajar a muy corta edad; la discriminación de género y la creencia de que por ser mujer no podía o no debía aprender; la distancia entre su casa y la escuela; o que su maestra o maestro no supo cómo enseñarle. Sea cual sea la razón particular como puede verse, no tiene nada que ver con su capacidad para aprender.

Seguidamente y durante todo el tiempo de la alfabetización, es muy importante la retroalimentación positiva, hacerle notar lo bien que está realizando alguna tarea por pequeña que parezca; el halago verbal ante la persona y también delante de sus familiares, gatilla la motivación. En este sentido, es fundamental hacerle saber sus progresos, hacerle ver lo que va avanzando, lo que va logrando.

Paralelamente, es muy conveniente reconocer sus habilidades en otras áreas de la vida cotidiana o laboral. Conversar sobre sus destrezas y capacidades y la importancia que ellas tienen en su vida y en las de otras personas contribuye a que la persona aprendiente se de cuenta de lo valiosa que es.

"La autoestima es uno de los elementos psicológicos más importantes en la valoración del adulto mayor, sobre la cual se requiere especial atención y fortalecimiento en el trabajo diario con el anciano" (Ortiz y Castro, 2009, p. 28). Con las personas adultas mayores se agudiza la necesidad de promover su autoestima, sobre todo en los ambientes donde no se valora la sabiduría que puede conllevar la experiencia de vida.

\section{Comensalidad}

Cada sesión es un tiempo para compartir, y ya sea que exista una relación previa entre quien aprende y quien enseña, o no, debe generarse un espacio propicio para conversar. Cuando conversamos estamos desarrollando la expresión oral y la escucha, áreas fundamentales en el aprendizaje de la lectura y la escritura. Además al conversar establecemos una relación más humana, más afectiva.

El diálogo surge con naturalidad en espacios no formales como por ejemplo cuando compartimos un refrigerio. Por ello en cada sesión debemos dedicar un tiempo para la comensalidad, o sea, para compartir algunos alimentos alrededor de una mesa; puede ser simplemente un refresco o un café, con un pedazo de pan o unas galletas. No obstante, esta actividad se vuelve un espacio de gran valor para desarrollar la familiaridad, la confianza, la cercanía entre quien enseña y quien aprende, así como también con otras personas que pueden formar parte de esa rutina. Esta actividad genera un clima de encuentro y de colaboración propio de la comunicación y favorece el proceso de mediación pedagógica de los aprendizajes. 
Como bien lo expresa Boff (2008): "Esa comensalidad que ayer nos hizo humanos, continúa todavía hoy haciéndonos siempre de nuevo humanos. Por eso, importa reservar tiempos para la mesa en su sentido pleno de la comensalidad y de la conversación libre y desinteresada" (párr. 7).

\section{Tareas extraclase}

La tarea extraclase en la alfabetización de personas jóvenes o adultas tiene el propósito de practicar lo aprendido o continuar explorando los conceptos estudiados. Pero no debe ser una carga o un problema para quien aprende. Por lo anterior, puede o no asignarse tareas, según lo quiera o no la persona que está aprendiendo a leer y a escribir. En todo caso no debe convertirse nunca en un escollo del proceso.

Si la persona quiere realizar tareas, estas deben ser sobre lo estudiado en la sesión, a manera de práctica. Deben generar satisfacción y sensación de progreso, por lo que no deben ser muy extensas.

\section{Materiales recomendados}

Como se mencionó anteriormente, los intereses y las necesidades de quien aprende son la fuente para determinar la metodología y, por lo tanto, también los materiales por utilizar.

Además, deben combinarse los intereses y las necesidades para darle más variedad a las actividades propuestas. Así, por ejemplo, puede ser que la necesidad de una persona de aprender a leer y a escribir sea para poder tomar los buses sola y, por lo tanto, el material recomendado sería los rótulos con los nombres de las rutas de los buses que frecuenta; pero, si sus intereses están alrededor de los textos bíblicos, los materiales de lectura y escritura que se desprenden de ello podrían ser versículos de la Biblia.

Los materiales de lectura que están en el medio, o materiales auténticos, no son elaborados para enseñar a leer y escribir; no obstante, son los más recomendables para la alfabetización de personas adultas, dado que se utilizan en situaciones contextualizadas de comunicación, tales como periódicos, libros, revistas, rótulos, afiches, instructivos, entre otros.

Puede verse, entonces, que existe diferencia entre los materiales didácticos y los materiales auténticos, dado que los primeros se elaboran con fines pedagógicos, mientras que los segundos, aunque se aprovechan en los procesos pedagógicos, no son elaborados con ese fin.

En cuanto a los materiales para escribir hay que considerar si la persona adulta ha desarrollado o no, la habilidad de trabajo con objetos pequeños y, por lo tanto, debe ir ubicándose en el espacio del papel paulatinamente, iniciando con hojas en blanco, luego hacerle renglones espaciados, para posteriormente proponerle escribir sobre renglones convencionales. El lápiz para escribir debe ser fuerte, pero no manchar, no debe usarse portaminas al inicio del proceso. 
doi: http://dx.doi.org/10.15359/ree.20-1.22

URL: http://www.una.ac.cr/educare

CORREO: educare@una.cr

Es positivo utilizar cuadernos "delgados" o con pocas hojas para que quien aprende a escribir lo concluya en un corto tiempo, pues terminar un cuaderno da la sensación de logro, e iniciar un cuaderno da la alegría de un nuevo comienzo dejando atrás lo pasado. Un cartón del tamaño de la hoja del cuaderno es cómodo para ponerlo detrás de la hoja que se está utilizando, evitando así que las marcas que se producen al escribir fuertemente, se pasen a la siguiente hoja. Por la misma razón en mejor escribir solo por el frente de cada hoja hasta que la persona pueda escribir de manera más suave.

\section{Tipos de texto}

En la vida cotidiana la persona adulta se relaciona con gran variedad de tipos de texto, por lo cual es prudente que se incluyan en el proceso de alfabetización. Es importante que quien aprende a leer y a escribir sepa interpretar el texto según sus características, así como también que pueda producir textos de diversos tipos según la intencionalidad de su comunicación.

La selección de los tipos de texto a incorporar se debe realizar según los intereses de quien aprende. Así, por ejemplo, si interesa la cocina, será vital trabajar con recetas; si se quiere hacer llegar un mensaje a otra persona, la carta es una posibilidad; si la persona quiere ayudar a sus hijos o nietos con las labores escolares, se puede integrar el cuento.

Es así como se pueden trabajar, además de los textos mencionados en el párrafo anterior, textos publicitarios como el aviso, el afiche o el folleto; textos humorísticos; de información científica; periodísticos o literarios.

\section{Tecnología}

En la vida moderna la tecnología forma parte de la cotidianidad, por lo cual puede ser una excelente herramienta a incorporar en la alfabetización de personas jóvenes y adultas.

Muchas veces aprender a escribiry enviar mensajes de texto mediante el teléfono celular se vuelve un elemento de la motivación. En esos casos se puede incorporar de manera sistemática la práctica de enviar mensajes de texto.

Cada texto tiene sentido en su contexto, y la enseñanza de la lectura y la escritura debe llevarse a cabo de manera pertinente, por lo cual no es un problema que en los mensajes de texto se usen abreviaturas $u$ otras formas que no corresponden al lenguaje erudito, pero que tienen un uso generalizado dado que sirven para la comunicación.

Si se tiene acceso a la computadora, esta puede ser también un excelente recurso que debemos aprovechar para explorar campos de interés de la persona que está aprendiendo a leer y escribir. 


\section{Proceso metodológico para mediar la construcción de la lectoescritura con personas jóvenes y adultas}

Como ya se comentó, cada proceso de alfabetización es diferente, es único, por lo tanto no es recomendable apegarse a un método, entendido como procedimientos rígidos que deben seguirse, sino más bien debe ser el sentido común y la intuición que surgen del conocimiento sistematizado, lo que oriente al mediador o mediadora de los aprendizajes, pero ubicando siempre a la persona aprendiente como centro del proceso.

Para ello es conveniente tener presente rutas de mediación de los aprendizajes que de manera flexible puedan favorecer la experiencia pedagógica. En ese sentido se comparte seguidamente la ruta del "Nombre propio".

El nombre propio está cargado de significado. Es una de las palabras más significativas para quien aprende a leer y escribir, es su identidad, le dignifica. Por ello es aconsejable iniciar la alfabetización con el nombre propio de cada aprendiente. Puede utilizarse en lugar del nombre, el sobrenombre o apodo si así es como le gusta a la persona ser nombrada.

Unido a lo anterior, la alfabetización tiene mucho mayor efecto, si se realiza en un ambiente grato, lúdico, donde el juego sea parte inherente de la metodología.

\section{Ruta del nombre propio}

\section{Identificar el nombre propio}

a. Solicite a la persona a quien usted va a enseñar a leer y a escribir que escriba su nombre. Si la persona le manifiesta no saber escribirlo, o lo escribe de manera inadecuada, preséntele su nombre y primer apellido en letras mayúsculas y en tarjetas separadas.

b. Promueva una conversación sobre su nombre y apellido. Por ejemplo: si algún antepasado se llamaba igual, de dónde proceden su nombre y apellido, si le gusta su nombre, si tiene apodos o algunas personas por cariño le llaman de otra forma.

c. Solicite que copie su nombre y apellido en una hoja blanca. Puede escribir en un cuaderno o en hojas sueltas, pero sin renglones. Si se usan cuadernos deben tener pocas páginas; como ya se mencionó, se recomienda poner una cartulina bajo la hoja donde se escribe para que no se marque la siguiente.

d. Comente que se lee o escribe de izquierda a derecha, así como también aproveche para conversar respecto a la forma de tomar el lápiz y de utilizar las hojas de papel o el cuaderno.

e. Converse sobre las semejanzas y diferencias entre el nombre y el apellido. Por ejemplo:

- Si hay letras que se repiten, identificarlas.

- Comentar la extensión que tiene cada palabra. ¿Cuál es más larga? ¿Cuántas letras tiene cada una? 
doi: http://dx.doi.org/10.15359/ree.20-1.22

URL: http://www.una.ac.cr/educare

CORREO: educare@una.cr

- Aprovechar las características que presente el nombre o el apellido, para comentar sobre ellas. Por ejemplo: Si hay tildes explique su uso específico. Si tiene las letras ("s" $y^{\prime \prime} z$ ") o ("b" $y^{\prime \prime} v$ ") comente al respecto.

- Comentar cuáles letras son vocales y cuáles consonantes.

- Introducir el resto de las vocales siempre desde una palabra.

f. Realice diversas actividades hasta que la persona no confunda su nombre y apellido con otras palabras.

Por ejemplo, si se trabaja con varias personas escriban todos los nombres y apellidos en tarjetas del mismo tamaño y color, revuélvanlas y cada uno tome los suyos; o escriban dos veces cada tarjeta y jueguen "Memoria", juego que consiste en colocar todas las tarjetas "boca abajo" y por turnos buscar las parejas.

Si el trabajo es con una sola persona incluya nombres de sus familiares y pídale que identifique las tarjetas con su nombre y apellido.

g. Introduzca el segundo apellido de la persona que alfabetiza. Realice actividades semejantes a las llevadas a cabo con su nombre y primer apellido.

\section{Reconocer las sílabas del nombre y de los apellidos}

a. Oralmente realice con la persona aprendiente la división silábica de su nombre y apellidos.

b. Pida a la persona participante que corte en sílabas tanto su nombre como sus apellidos escritos en tarjetas.

c. Invítele a volver a armar el nombre y los apellidos. Primero contando con el nombre completo como modelo y posteriormente sin tener presente el modelo.

d. Pida que los copie nuevamente.

e. Explique que toda palabra está formada por sílabas.

f. Realicen ejercicios orales de división silábica utilizando diversas palabras.

g. Reafirmen la división silábica dando una palmada por cada sílaba, así como posteriormente, anotando una rayita por cada sílaba emitida.

h. Tome cada una de las sílabas del nombre y de los apellidos de la persona participante y pídale que exprese oralmente palabras que empiecen con la sílaba seleccionada. Usted las puede ir escribiendo en una hoja o en una pizarra ante la vista de quien la dijo. Si la persona participante se interesa, puede copiarlas.

i. Si es posible formen algunas palabras utilizando las sílabas con que se cuenta, invite a su escritura y conversen sobre su significado.

Si trabaja con un grupo, propicie actividades donde se compartan las sílabas y se formen con ellas nuevas palabras. Primero en parejas y posteriormente en tríos. También invite a realizar juegos usando las sílabas de los nombres y apellidos. Por ejemplo, "El barco 
se hunde". Este juego se realiza de la siguiente manera: Cada participante toma una tarjeta con una de sus sílabas y se desplazan por la habitación, si es posible con música de fondo. El o la facilitadora indica cada cierto tiempo que "El barco se hunde y se salvan quienes se ubiquen en botes de __. . Aquí varía el número $(3,2,4)$ ante lo cual los participantes deben formar palabras con el número de sílabas indicado, juntando las sílabas de unos y otros. Se aplaude a los ganadores y se reinicia el juego.

j. Presente ahora el nombre y apellidos usando mayúsculas solamente en las letras iniciales.

k. Converse sobre las semejanzas y diferencias entre el nombre y apellidos. Por ejemplo:

- Que inician con mayúscula. Aproveche para conversar respecto a la diferencia entre letras mayúsculas y minúsculas, así como su utilización.

- Comenten las características de algunas letras. Por ejemplo que hay algunas más altas (de dos cuerpos como la "ele") y que otras "bajan" del renglón, si es el caso.

I. Solicite cortar en sílabas las palabras de las nuevas tarjetas, (nombre y apellidos usando mayúsculas y minúsculas) volver a formarlas y copiarlas.

\section{Particularizar las letras del nombre y de los apellidos}

a. A partir de lo anterior, corten ahora las sílabas escritas en tarjetas, en letras.

b. Vuelvan a "armar"el nombre y apellidos usando las letras recortadas. (Primero contando con el modelo y luego sin él.) Luego escríbanlo.

c. Busquen en el periódico las letras del nombre y apellidos, una vez recortadas péguenlas en una hoja formando nuevamente nombre y apellidos.

d. Utilicen las letras para formar nuevas palabras. Para ello se puede jugar “¿Qué esconde mi nombre? Este consiste en utilizar cuantas veces sea necesario las letras que integran el nombre y apellidos para escribir nuevas palabras.

Podemos buscar por categorías, por ejemplo, si hay colores ocultos, frutas o animales. Si estamos trabajando con un grupo de personas, se procede a "PRESTARSE LETRAS", primero en parejas y luego en subgrupos y de esta manera cada participante puede compartir sus letras y ampliar el número de palabras formadas.

Si el trabajo es con una sola persona podemos prestarnos letras usando el nombre y apellidos de quien aprende y de quien enseña.

e. Invite a la formación oral de rimas, utilizando algunas de las palabras escritas.

\section{Conocer nuevas letras a partir del nombre y de los apellidos}

A partir de este momento se propicia la realización de diversas actividades que permitan conocer nuevas letras, pero hay que recordar que deben ubicarse en palabras con sentido. Se recomiendan las siguientes: 
doi: http://dx.doi.org/10.15359/ree.20-1.22

URL: http://www.una.ac.cr/educare

CORREO: educare@una.cr

- Escribir el nombre en columnas y buscar en revistas o periódicos imágenes cuyo nombre inicie con cada letra escrita, recortarlas y pegarlas. Abajo escribir la nueva palabra con apoyo del facilitador o facilitadora.

- Escribir el nombre verticalmente y a su lado, con ayuda del facilitador o la facilitadora, escribir una cualidad de la persona, que inicie o termine con esa letra. (Es muy importante utilizar solamente términos positivos, si no se encuentra cualidad para alguna letra, se deja sin llenar).

\section{Lectoescritura de textos}

Los intereses de la persona que está aprendiendo a leer y escribir, constituyen

el eje del trabajo a partir de este momento para la lectoescritura de textos. Así por ejemplo y como se mencionó anteriormente:

- Si quiere aprender para leer la Biblia, se debe trabajar con versículos tomados de ella.

- Si le gusta cocinar, se trabaja con recetas de cocina.

- Si su oficio es la carpintería, se puede iniciar con los nombres de las diversas herramientas.

- Si la persona desea ayudar a sus hijos, sería conveniente utilizar cuentos infantiles.

- Si la motivación consiste en realizar el examen para obtener licencia de conducir, se puede utilizar como texto principal la guía de estudio para dicho examen.

Lo importante es considerar las razones que motivan a la persona para aprender a leer y escribir, sus gustos e intereses. Una vez determinado lo anterior, se seleccionan los textos para continuar con la mediación pedagógica del aprendizaje, leyéndolos, comentándolos, escribiendo a partir de ellos.

\section{A manera de conclusión}

La alfabetización de personas jóvenes y adultas no se limita a leer y a escribir palabras, sino que tiene que ver con la dignidad, con la valoración de la persona integralmente, con saber que se puede seguir aprendiendo durante toda la vida, y que se tiene el derecho a ser libre, participar, pronunciarse y soñar. Tiene que ver con la alegría de vivir y convivir; de enfrentar los miedos y de ser independiente; con valorar el esfuerzo y la perseverancia.

En la convivencia de la alfabetización aprenden tanto el mediador o la mediadora, como la persona aprendiente. Para quien realiza la mediación de los aprendizajes de la lectura y la escritura es una experiencia significativa que marca y enriquece su vida. Como expresa Maturana (2001):

El educar se constituye en el proceso en el cual el niño o el adulto convive con otro y al convivir con el otro se transforma espontáneamente, de manera que su modo de vivir se hace progresivamente más congruente con el otro en el espacio de convivencia. (p. 18) 
La alfabetización continúa siendo un reto para nuestras colectividades. Los motivos del analfabetismo se encuentran fundamentalmente en la pobreza, la inequidad social, la marginación, la discriminación por género, así como en la falta de preparación de docentes que no logran que sus niños y niñas escolares aprendan a leer, escribir, expresarse y crear, durante su infancia.

Las personas adultas que aún no han aprendido a leer y a escribir siguen manteniéndose invisibilizadas y constituyen un desafío para las sociedades democráticas.

Realizar una experiencia de alfabetización entre personas jóvenes y adultas es abrirse a nuevas maneras de relación social, más solidarias, más respetuosas. Es sabernos parte del entramado de la vida, nunca acabado... siempre aprendiente.

\section{Referencias}

Amador, L., Monreal, M. y Marco, M. J. (2001). El adulto: Etapas y consideraciones para el aprendizaje. España: Eúphoros, 3, 97-112. Recuperado de http://dialnet.unirioja.es/ servlet/articulo?codigo $=1183063$

Boff, L. (2008). Comensalidad: Rehacer la humanidad. Koinonia. Recuperado de http://www. servicioskoinonia.org/boff/articulo.php?num $=272$

Ferreiro, E. (1997). La construcción de la escritura en el niño. Lectura y Vida. Revista latinoamericana de lectura, 12(3), 5-14). Recuperado de http://www.lecturayvida.fahce.unlp.edu.ar/ numeros/a12n3/12 03 Ferreiro.pdf

Ferreiro, E. (2007). Alfabetización de niños y adultos. Textos escogidos. México: Paideia Latinoamericana.

Flores, L. E. (2010). El placer de aprender. Revista Electrónica Educare, 14 (extraordinario), 41-47. Recuperado de http://www.revistas.una.ac.cr/index.php/EDUCARE/article/view/1526

Frei Betto. (2006). Educar para la ciudadanía. ALAl, América Latina en Movimiento. Recuperado de http://alainet.org/active/13640\&lang=es

Freire, P. (1991). La importancia de leer y el proceso de liberación. México: Siglo XXI.

Freire, P. (2004a). Cartas a quien pretende enseñar. Argentina: Siglo XXI.

Freire, P. (2004b). Pedagogía de la autonomía. Sao Paulo: Paz e Terra.

Maturana, H. (2001). Emociones y lenguaje en educación y política. Santiago de Chile: Dolmen.

Morin, E. (2001). Los siete saberes necesarios para la educación del futuro. Barcelona: Paidós. 
doi: http://dx.doi.org/10.15359/ree.20-1.22

URL: http://www.una.ac.cr/educare

CORREO: educare@una.cr

Ortiz, J. B. y Castro, M. (2009). Bienestar psicológico de los adultos mayores, su relación con la autoestima y la autoeficacia. Contribución de enfermería. Ciencia y Enfermería, 15(1), 2531. Recuperado de http://www.scielo.cl/pdf/cienf/v15n1/art04.pdf

\section{(C) Cómo citar este artículo en APA:}

Flores-Davis, L. E. (Enero-abril, 2016). Alfabetización entre personas jóvenes y adultas. Revista Electrónica Educare, 20(1), 1-16. doi: http://dx.doi.org/10.15359/ree.20-1.22

Nota: Para citar este artículo en otros sistemas puede consultar el hipervínculo "Como citar el artículo" en la barra derecha de nuestro sitio web: http://www.revistas.una.ac.cr/index.php/EDUCARE/index 